\title{
Visual detection and characterization of chronic myocardial infarctions in patients using native $T_{1}$ maps at $3 \mathrm{~T}$
}

\author{
Avinash Kali ${ }^{1 *}$, Eui-Young $\mathrm{Choi}^{2}$, Behzad Sharif ${ }^{1}$, Young Jin $\mathrm{Kim}^{2}$, Xiaoming Bi ${ }^{3}$, Bruce S Spottiswoode ${ }^{3}$, Ivan Cokic ${ }^{1}$, \\ Hsin-Jung Yang ${ }^{1}$, Mourad Tighiouart', Debiao Li ${ }^{1}$, Daniel S Berman', Byoung Wook Choi ${ }^{2}$, Hyuk-Jae Chang ${ }^{2}$, \\ Rohan Dharmakumar'
}

From 18th Annual SCMR Scientific Sessions

Nice, France. 4-7 February 2015

\section{Background}

Late Gadolinium Enhancement (LGE) Cardiovascular Magnetic Resonance (CMR) is routinely used for characterizing chronic myocardial infarctions (cMIs), but it is contraindicated in patients with end-stage chronic kidney disease. We investigated whether native $\mathrm{T}_{1}$ mapping at $3 \mathrm{~T}$ can be used to detect and characterize cMIs in patients with prior STEMI and NSTEMI.

\section{Methods}

Breath-held 2D native $\mathrm{T}_{1}$ maps (8 TIs with 2 Look-Locker cycles of $3+5$ images; minimum $\mathrm{TI}=120 \mathrm{~ms}$; TI increment $=80 \mathrm{~ms}$; flip angle $=35^{\circ}$; bandwidth $=1085 \mathrm{~Hz} /$ pixel; voxel size $=1.5 \times 1.5 \times 8 \mathrm{~mm}^{3}$ ) and LGE images (IR-prepared FLASH; optimal TI to null remote myocardium; TR/TE = $6.54 / 3.27 \mathrm{~ms}$; flip angle $=20^{\circ}$; bandwidth $=460 \mathrm{~Hz} /$ pixel; voxel size $\left.=1.2 \times 1.2 \times 8 \mathrm{~mm}^{3}\right)$ were acquired in patients with prior STEMI $(\mathrm{n}=15)$ and NSTEMI $(\mathrm{n}=17)$ at $3 \mathrm{~T}$ at a median of 13.6 years after acute MI. cMI location, size and transmurality were determined using Mean +5 SD criterion relative to remote myocardium. Visual detection of cMI territories on LGE images and $\mathrm{T}_{1}$ maps were assessed by two independent reviewers.

\section{Results}

Representative native $\mathrm{T}_{1}$ maps and LGE images from two patients, one with prior STEMI, and one with prior NSTEMI are shown in Fig. 1. Relative to remote myocardium, median $\mathrm{T}_{1}$ of the cMI was $271 \mathrm{~ms}$ higher in STEMI patients (Infarct: $1517 \mathrm{~ms}$; Remote: $1247 \mathrm{~ms}$;

${ }^{1}$ Cedars-Sinai Medical Center, Los Angeles, CA, USA

Full list of author information is available at the end of the article $\mathrm{p}<0.001$; Fig. 1), and $229 \mathrm{~ms}$ higher in NSTEMI patients (Infarct: $1549 \mathrm{~ms}$, Remote: $1262 \mathrm{~ms} ; \mathrm{p}<0.001$; Fig. 1). Median percentage change in LGE signal intensity (LGE-SI) of the cMI relative to remote myocardium was significantly higher than that of percentage change in $\mathrm{T}_{1}$ in both STEMI (LGE: 465\%, $\mathrm{T}_{1}: 21 \% ; \mathrm{p}<0.001$ ) and NSTEMI (LGE: 441\%, $\mathrm{T}_{1}: 20 \% ; \mathrm{p}<0.001$ ) patients. Median CNR of LGE images was also 2.5-fold higher relative to that of $\mathrm{T}_{1}$ maps in both STEMI (LGE: 23.1; $\mathrm{T}_{1}$ : 9.2; $\mathrm{p}<0.001$ ) and NSTEMI (LGE: 25.3; $\mathrm{T}_{1}: 9.7 ; \mathrm{p}<0.001$ ) patients. LGE images and native $\mathrm{T}_{1}$ maps were not different for measuring cMI size (STEMI - LGE: $13.8 \%$; $\mathrm{T}_{1}$ : 14.9\%; $\mathrm{p}=0.87$; NSTEMI - LGE: $10.9 \% ; \mathrm{T}_{1}: 10.5 \%$; $\mathrm{p}=0.93$; Fig. 2) and transmurality (STEMI - LGE: 55.6\%; $\mathrm{T}_{1}$ : 60.1\%; $\mathrm{p}=0.19$; NSTEMI - LGE: 64.3\%; T1: 60.9\%; $\mathrm{p}=0.24)$. Statistical analyses showed good agreement between LGE images and $\mathrm{T}_{1}$ maps for measuring cMI size (STEMI: bias $=-0.4 \pm 2.1 \%$; $\mathrm{R}^{2}=0.97$; NSTEMI: bias $=-$ $1.1 \pm 3.9 \% ; \mathrm{R}^{2}=0.87$ ) and transmurality (STEMI: bias $=1.5 \pm 2.9 \% ; R^{2}=0.99$; NSTEMI: bias $=-2.2 \pm 7.4 \%$; $\mathrm{R}^{2}=0.71$ ). Sensitivity and specificity of native $T_{1}$ maps for detecting cMIs based on threshold criterion were 93\% and $97 \%$ respectively (STEMI); and 93\% and 92\% respectively (NSTEMI). Sensitivity and specificity of native $\mathrm{T}_{1}$ maps for visual detection of cMI were: $61 \%$ and $85 \%$ (STEMI); and $67 \%$ and $90 \%$ (NSTEMI).

\section{Conclusions}

Native $T_{1}$ maps can reliably detect and characterize cMIs in STEMI and NSTEMI patients when the location of remote myocardium is known. Further increase in image contrast may be necessary to improve visual 


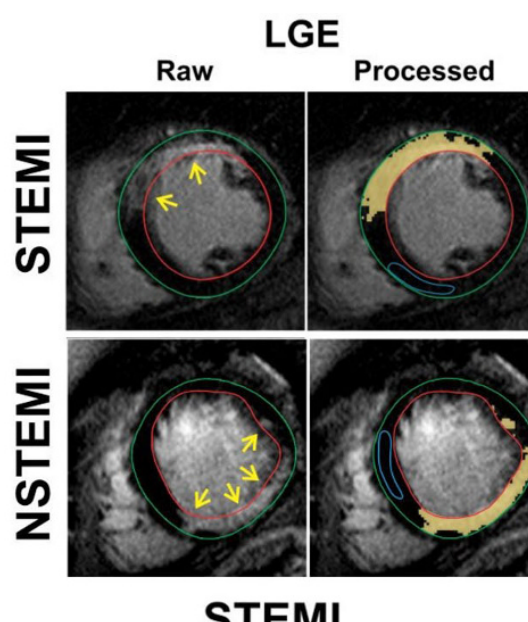

STEMI

A
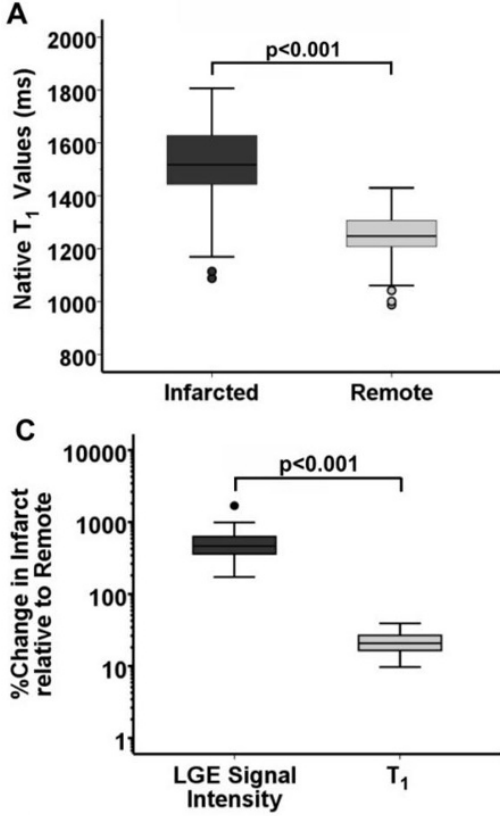

E

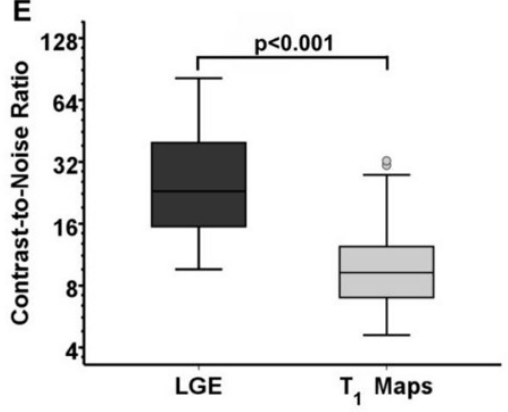

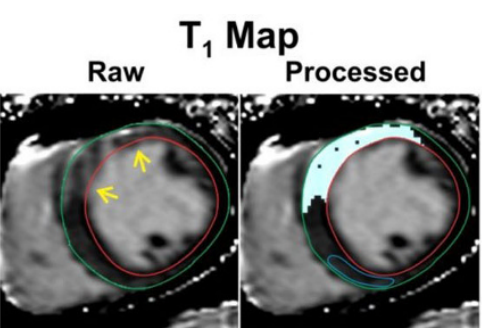

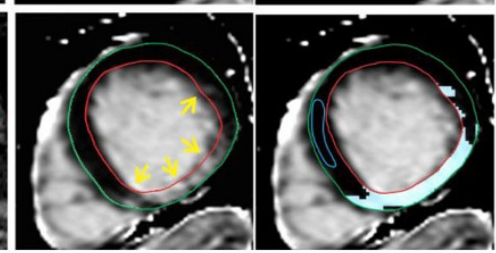

NSTEMI

B
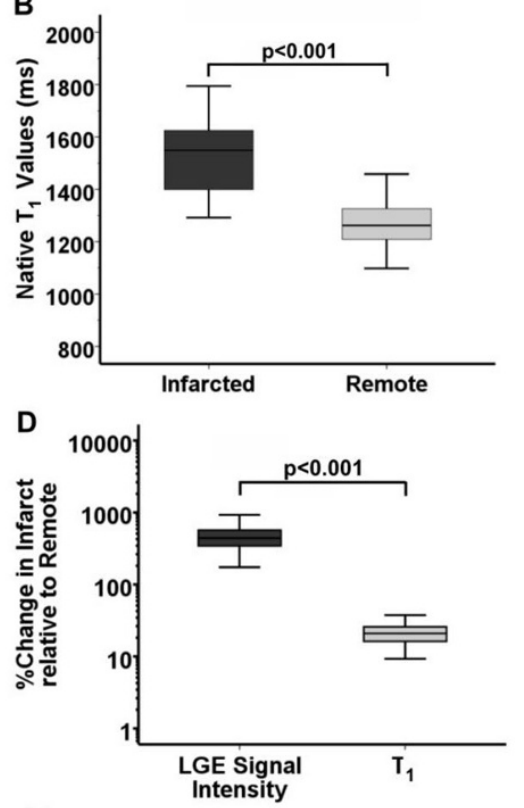

F

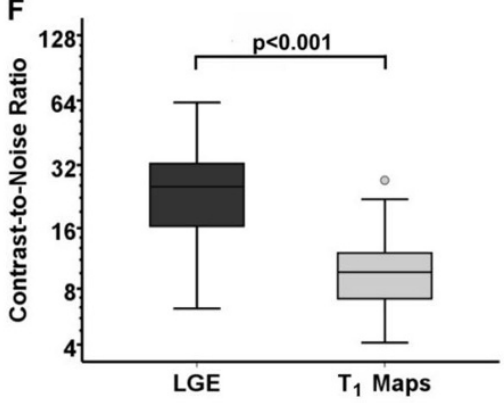

Figure 1 Representative native T1 maps and LGE images from a patient with prior STEMI (infarct age $=18.5$ years) and NSTEMI (infarct age $=$ 25.6 years) are shown. Significant T1 elevations could be observed within the infarcted regions detected on LGE images (arrows). Good visual agreement was observed between the two techniques in terms of the location and spatial extent of the infarct. Median native T1 of the infarct was significantly elevated in both STEMI and NSTEMI patients. Percentage change in LGE signal intensity and infarct-to-remote CNR was significantly in LGE images were significantly higher than that of T1 maps. 


\section{INFARCT SIZE COMPARISON}

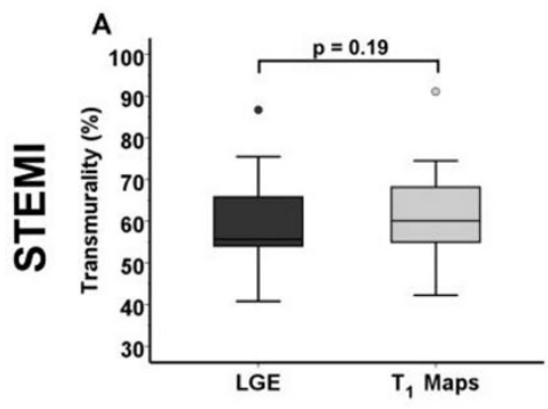

C

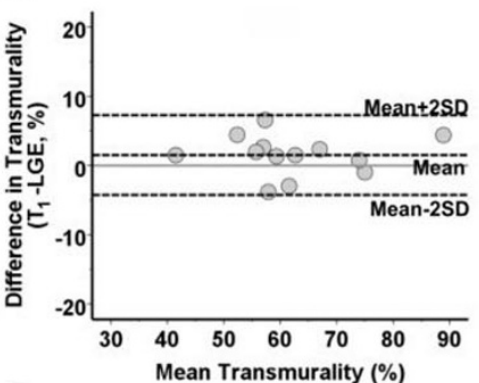

B

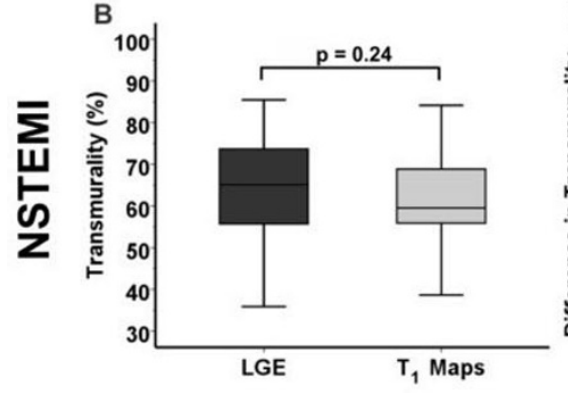

E

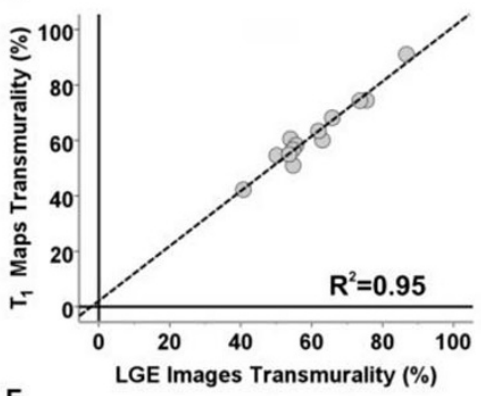

$\mathbf{F}$

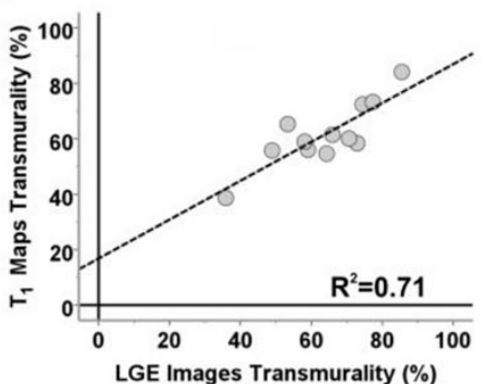

\section{TRANSMURALITY COMPARISON}

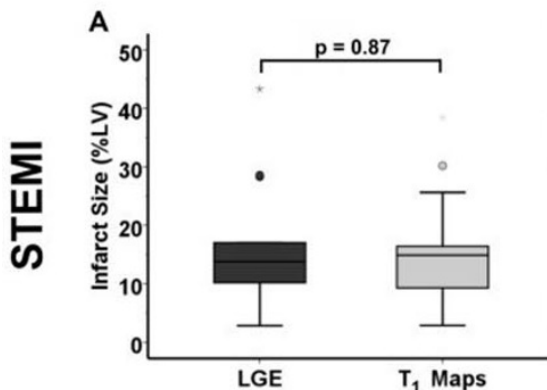

B

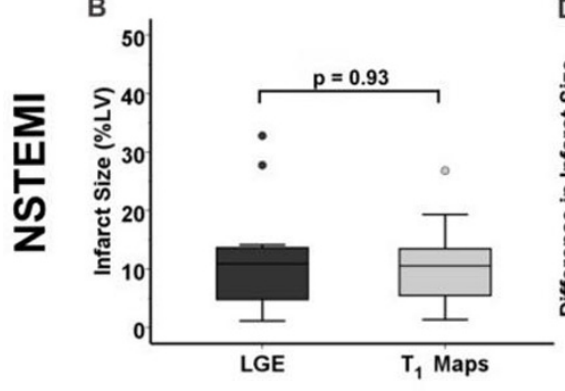

C

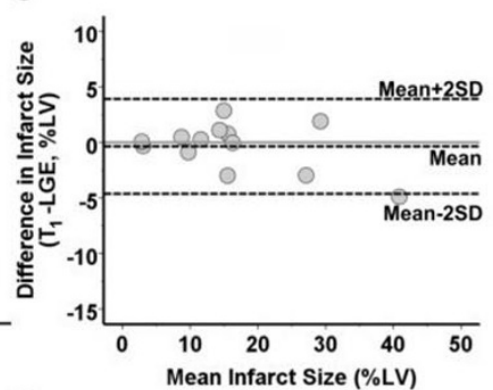

D

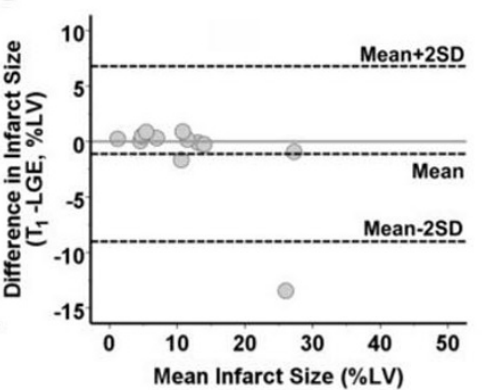

E

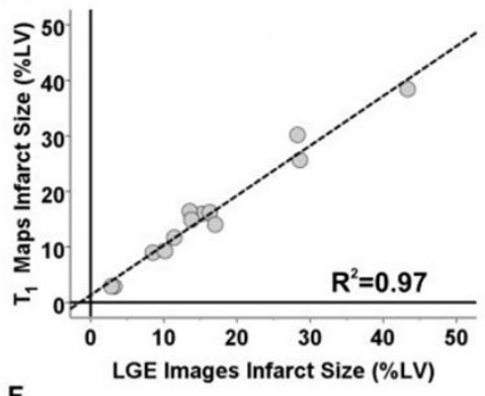

$\mathbf{F}$

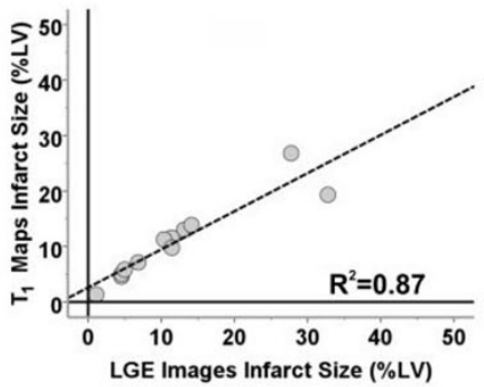

Figure 2 Native T1 maps and LGE images were not different for measuring chronic infarct size and transmurality in both STEMI and NSTEMI patients. Bland-Altman and linear regression analyses further showed good agreement for measuring infarct size and transmurality. 
detection sensitivity of chronic MI territories to the levels observed with LGE.

\section{Funding}

National Heart, Lung, and Blood Institute (RO1 HL091989) and American Heart Association Pre-Doctoral Fellowship (13PRE17210049).

\section{Authors' details}

${ }^{1}$ Cedars-Sinai Medical Center, Los Angeles, CA, USA. ${ }^{2}$ Yonsei University College of Medicine, Seoul, Korea (the Republic of. ${ }^{3}$ Siemens Healthcare, Los Angeles, CA, USA.

Published: 3 February 2015

\section{doi:10.1186/1532-429X-17-S1-074}

Cite this article as: Kali et al:: Visual detection and characterization of chronic myocardial infarctions in patients using native $\mathrm{T}_{1}$ maps at $3 \mathrm{~T}$.

Journal of Cardiovascular Magnetic Resonance 2015 17(Suppl 1):O74.

Submit your next manuscript to BioMed Central and take full advantage of:

- Convenient online submission

- Thorough peer review

- No space constraints or color figure charges

- Immediate publication on acceptance

- Inclusion in PubMed, CAS, Scopus and Google Scholar

- Research which is freely available for redistribution

Submit your manuscript at www.biomedcentral.com/submit 